\title{
Analysis of the possibilities of using reference wind measurements in the calculation of energy production from wind farms on low complex terrains
}

\author{
Angel Terziev, ${ }^{1 *}$ \\ ${ }^{1}$ Department of Power Engineering and Power Machines, Technical University of Sofia, 8 Kliment \\ Ohridski blvd., 1000 Sofia, Bulgaria
}

\begin{abstract}
The present paper analyses the possibility of using reference wind measurements in the estimation of energy production from wind farms on less complex terrains. For the purposes of the analysis the chosen site is located about $20 \mathrm{~km}$ from the closest point of the reference measurements. A correlation was made between the proposed data from the reference measurements and the wind parameters were extrapolated to the wind farm site. The results of the study were compared with experimental ones, while giving recommendations for refinement of the results when using reference data.
\end{abstract}

\section{Introduction}

The construction of a wind park is always preceded by a serious analysis of the wind potential in the vicinity of the site. Performing meteorological measurements with a high meteorological mast for a period longer than one year is more than mandatory, and correlation of measurement data with long-term ones.

In cases where the relief is relatively flat, reference measurements in the vicinity of the site of about $20-30 \mathrm{~km}$ could be used as reference data. In complex terrain, however, the use of reference data is accompanied by an accurate analysis of the terrain features and the roughness factor of the relief.

Papers [1-5] describe the influence of factors on energy production from wind farms installed on flat and complex terrains. Methods for numerical modelling of parameters in the vicinity of the wind park are proposed. In all cases investigated, however, long-term measurements were conducted in close proximity to the site of a wind farm. In [6-8] is presented the influence of the wind shear on the energy production from the wind park. An in-depth analysis of the parameters influencing the energy production from wind farms is presented in [9]. Using the reference measurements in the determination of energy production is presented in [10] and [11]. A few studies only considered the possibility for using only reference measurements in the determination of wind power generation, which is the focus of the current work.

\footnotetext{
*Corresponding author: aterziev@tu-sofia.bg
} 


\section{Site specifics}

The site is located in north-eastern part of Bulgaria, General Toshevo Municipality, close to the Romanian border. The terrain is $32 \mathrm{~km}$ west of the Black Sea cost and a few kilometres from the abovementioned town.

The terrain is relatively flat, as the elevation changes between 170 and $190 \mathrm{~m}$. Toward West direction the elevation increases slightly up to $200 \mathrm{~m}$ while the site is freely exposed towards the all entire sectors. Small hedges and lines of trees are traceable in the vicinity of the site. The most visible obstacles are the nearby located Kardam village and industrial complex (Figure 1).

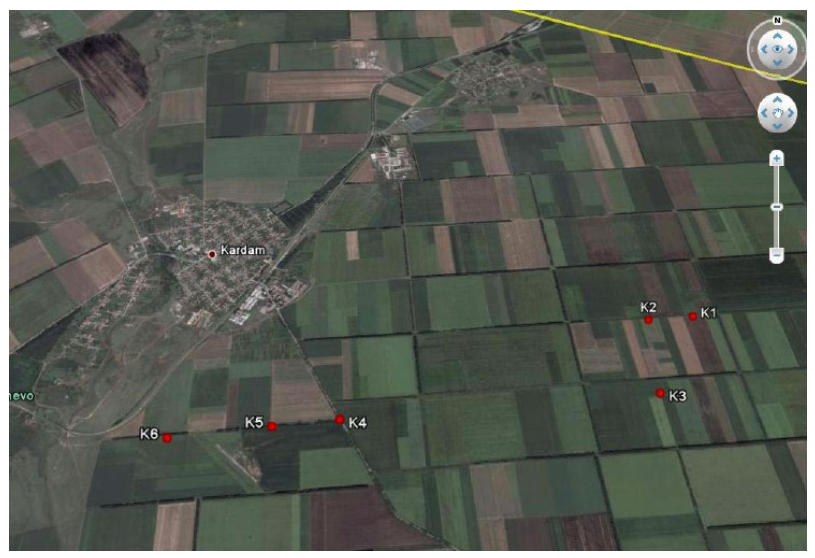

Fig. 1. Arial view of the selected site and nearby obstacles.

Six wind turbines are installed as wind turbine micro-sitting is based on the reference wind prevailing data.

\subsection{Long-term weather data}

Generally, the wind climate in Bulgaria is characterized both by seasonal pressure centres and strong orographic influence. The wind rose obtained from the World Wind Atlas for the site is presented in Figure 2.

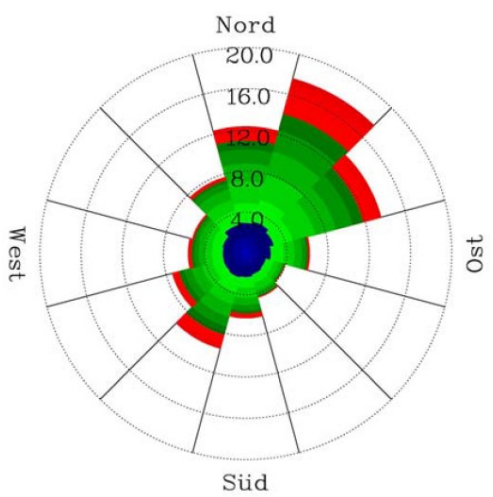

Fig. 2. Arial view of the selected site and nearby obstacles.

Three different reference sources in the vicinity of the site have been concerned during the analysis phase. The location of the reference sites are presented in Fig. 3. 


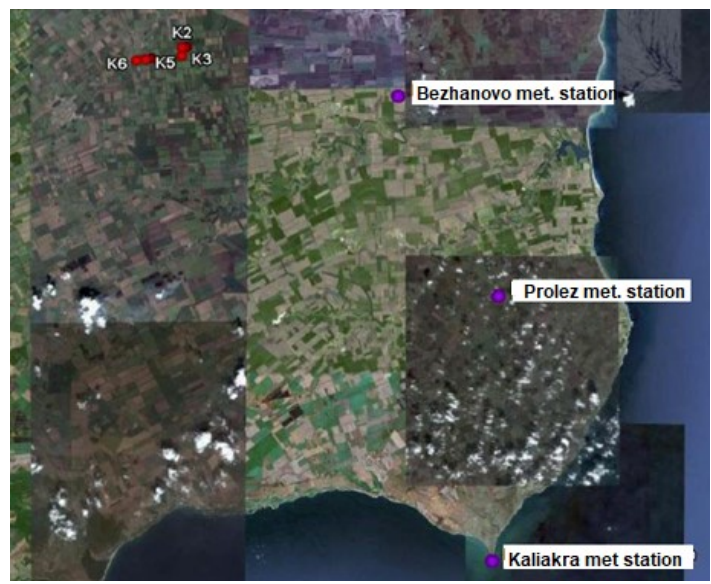

Fig. 3. Reference wind parameter sources.

Kaliakra meteorological station is located $38 \mathrm{~km}$ southeast of the high mast installed in Bezhanovo. It has archived data on wind speed over a period of 10 years. The meteorological mast in Bezhanovo is located $17.5 \mathrm{~km}$ east of the wind park, the terrain is relatively flat and the altitude is significantly lower $(96 \mathrm{~m})$ than the park site. The meteorological mast is $50 \mathrm{~m}$ high and has recordings of wind parameters for a two-year period. The wind speed is measured at three heights - 50, 30 and $25 \mathrm{~m}$, and wind direction 50 and $35 \mathrm{~m}$. The average wind speed based on the collected on-site data are as follow:

- $50 \mathrm{~m}-5.99 \mathrm{~m} / \mathrm{s}$

- $35 \mathrm{~m}-5.40 \mathrm{~m} / \mathrm{s}$

- $20 \mathrm{~m}-4.85 \mathrm{~m} / \mathrm{s}$

The wind shear based on the collected wind data implies a non-logarithmic velocity profile above the ground. The power law exponent based on the raw data is 0.291 . This shows that the effect of topography can be excluded due to the flat terrain, as the acceleration of the wind is due to light natural heights and the presence of trees (Figure 4).

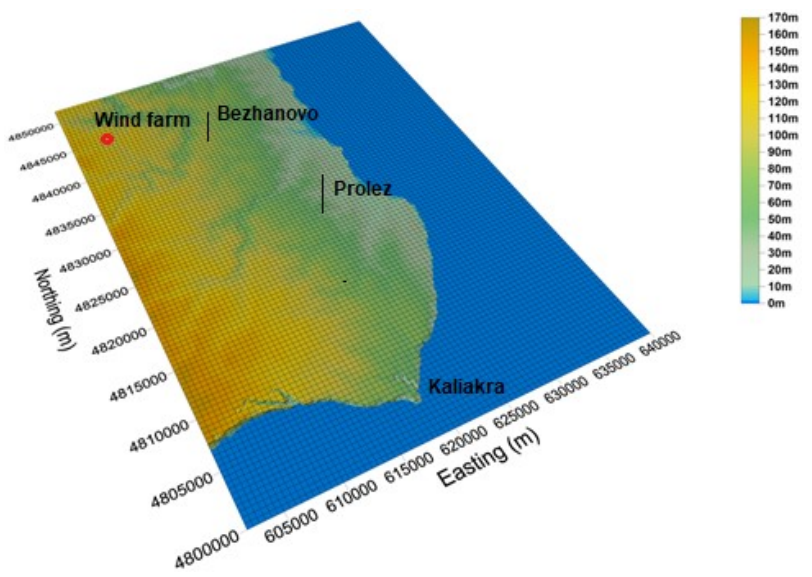

Fig. 4. 3D topography of the relief with wind park location.

Table 1 shows the correlation coefficient between the masts. It is obvious that the correlation coefficient between the masts installed in Prolez and Bezhanovo is the highest because of which they will be used with the greatest weight in determining the parameters of the site. 
Table 1. $\mathrm{r}^{2}$ - correlation coefficients for the measurement period, long-term for met station and grid data.

\begin{tabular}{|l|c|c|c|}
\hline & Kaliakra & Shabla & Bezhanovo \\
\hline Kaliakra & 1 & & 0.675 \\
\hline Shabla & 0.01 & 1 & 0.602 \\
\hline Prolez & 0.7 & 0.65 & 0.907 \\
\hline
\end{tabular}

\subsection{Numerical modelling}

Wind potential for the site was calculated using WAsP model in respect with local orography and roughness elements. The model was adjusted (calibrated) in accordance with performed measurements with tall tower and other reference sites. The proposed model is a linear that combine two models - physical model (atmosphere stability, roughness factor, relief change etc.) and statistical model (Weibull wind distribution). The physical model is used to determine the wind shear profile.

The model output value for the wind speed is $6.90 \mathrm{~m} / \mathrm{s}$. Directional distribution of the wind speed is presented in figure 5. The prevailing directions of the wind are three - from the North; North-Northwest and South-Southwest. In addition, the numerical survey shows $1.8 \%$ impact of the terrain on the wind speed profile by height.

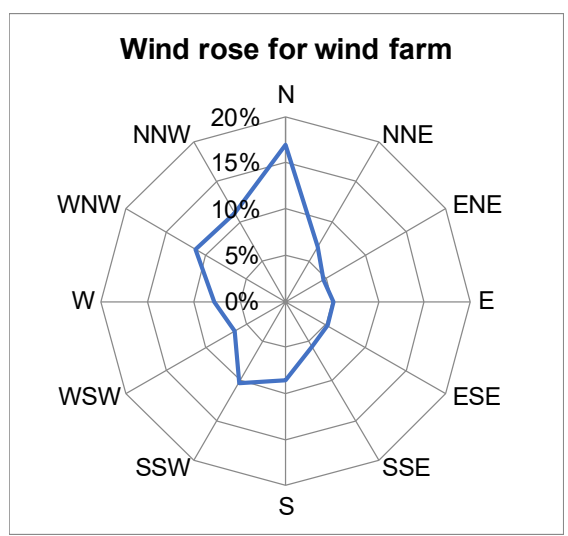

Fig. 5. Wind rose for the wind farm site (numerical study results)

Table 2. Numerical results for the wind parameters at hub height.

\begin{tabular}{|c|c|c|c|c|}
\hline Sector & Degrees & Wind speed, $\mathbf{n} / \mathbf{s}$ & Weibull A & Direction, \% \\
\hline N & $345-15$ & 7.8 & 8.8 & 17 \\
\hline NNE & $15-45$ & 6.9 & 7.7 & 6.9 \\
\hline ENE & $45-75$ & 6.9 & 7.8 & 4.6 \\
\hline E & $75-105$ & 5.9 & 6.7 & 5.1 \\
\hline ESE & $105-135$ & 5.5 & 6.2 & 5.2 \\
\hline SSE & $135-165$ & 5.8 & 6.5 & 5.7 \\
\hline S & $165-195$ & 6 & 6.7 & 8.6 \\
\hline SSW & $195-225$ & 6.5 & 7.3 & 10.2 \\
\hline
\end{tabular}




\begin{tabular}{|c|c|c|c|c|} 
WSW & $225-255$ & 6.8 & 7.5 & 6.5 \\
\hline W & $255-285$ & 7.5 & 8.5 & 7.8 \\
\hline WNW & $285-315$ & 8 & 9 & 11.3 \\
\hline NNW & $315-345$ & 7.1 & 8 & 11.1 \\
\hline Mean/sum & & 6.9 & 7.8 & 100 \\
\hline
\end{tabular}

Table. 2 shows information about wind parameters for the wind turbine hub height in the vicinity of the wind farm site.

\section{Site specifics}

\subsection{On-site measurements and data analysis}

At the end of 2010, the selected wind park was put into operation. The wind turbines are of a new generation, with an installed capacity of $2.1 \mathrm{MW}$ and equipped with a modern SCADA system for recording the data from the turbine operation. Said system reports a number of ambient air parameters, including real-time wind turbine performance.

Thus, in 2011, the average wind speed of the wind turbine hub $(79 \mathrm{~m})$ is $5.3 \mathrm{~m} / \mathrm{s}$ or about $23.18 \%$ lower than the numerically calculated. In 2012 the measurement period is 8 months (January-September). The average speed for the period is $5.53 \mathrm{~m} / \mathrm{s}$ and is about $7.7 \%$ lower than the numerically predicted.

In addition, differences in the directional statistic between the numerical results and the field measurements (Figure 6) are observed. The correlation of the data between the forecast and on-site measurements in 2011 is $33 \%$, and the same correlation in 2012 is $38.5 \%$. The correlation is low, indicating that, for the period, the wind has features that differ from long term data. Considering that the data is extrapolated to the point of the wind farm, increases the error from numerical studies. For this reason, measurements of the wind parameters in a nearby area are mandatory.

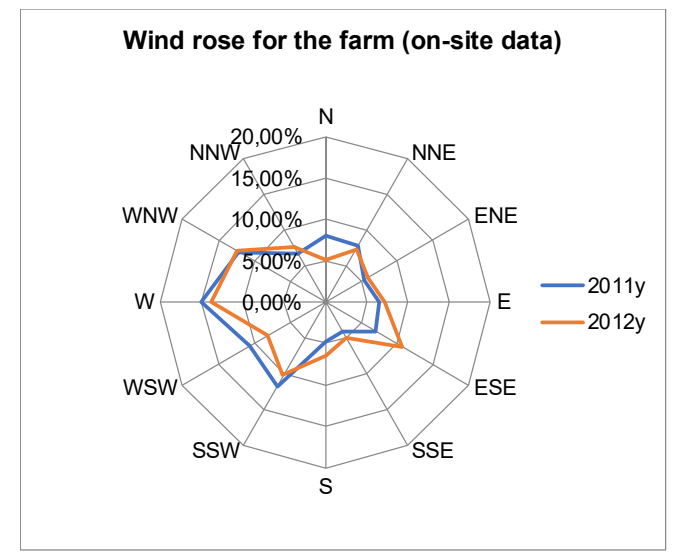

Fig. 6. Wind rose for the wind farm site (on-site data).

Fig. 7 is a variation of the average speed for a two-year period of turbine operation at a hub height of $79 \mathrm{~m}$. There is a good match between the average monthly speed for both years. 


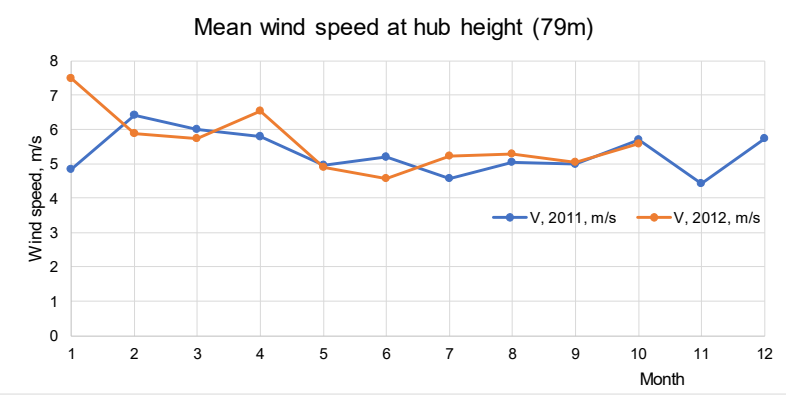

Fig. 7. Wind speed at the hub height (on-site data)

\subsection{Wind energy production from the farm}

The wind farm includes six Suzlon S88 turbines each with an installed capacity of 2.1 MW or a total of $12.6 \mathrm{MW}$. The rotor diameter of the wind turbine is $88 \mathrm{~m}$ and the turbine hub height is $79 \mathrm{~m}$. The power curve of the turbine is shown in Fig. 8. The turbines are grouped in three, being at a distance of about $3 \mathrm{~km}$ from each other, implying similar energy production because of the similar wind parameters and technical specifics of the machines.

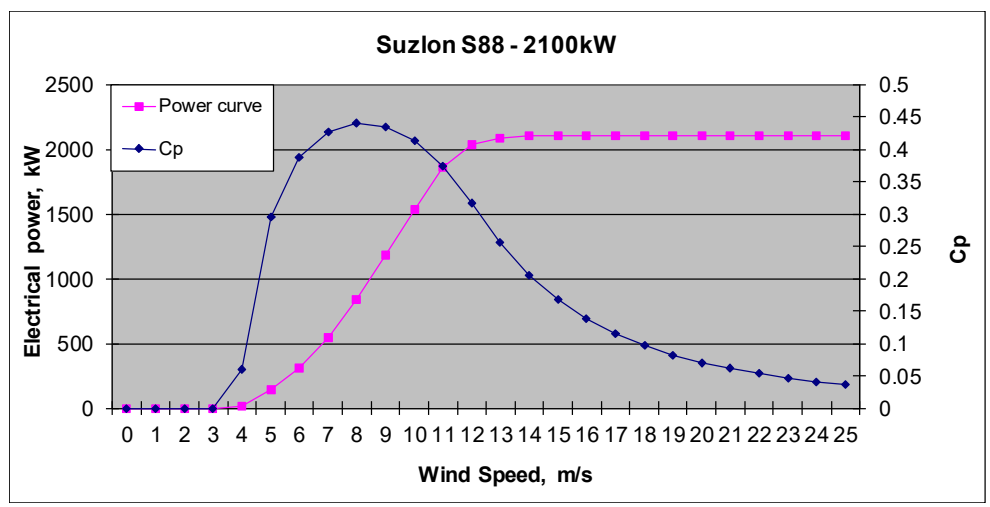

Fig. 8. Power curve of the Suzlon S88 wind turbine

Fig. 9 shows invoiced (actually produced) electricity from all wind turbines in the park per $1 \mathrm{MW}$ installed power.

The analysed period includes the time interval January - September 2012 (Figure 9). The correlation between electricity generation data is about $99.6 \%$, which shows that, with respect to wind potential, production from all wind turbines is comparable (wind turbines 1 , 2 and 3 are reported as Kardam 1 wind farm; wind turbines 4, 5 and 6 are reported as Kardam 2 wind farm). This, in turn, excludes technical failure in one or several machines in terms of the electricity produced. Because of the above, the potential reason for the difference between actual and estimated energy production is the potential of the wind in the vicinity of the site.

Fig. 10 shows a comparison of the energy produced by turbines in Kardam 1 and 2 Wind Park, as well as a long-term assessment of the potential of the site. Correlation of data between 2012 and the long-term ones is about 98\%. Energy production in 2012 compared to long-term is $26 \%$ lower. A lower correlation between data is observed between longterm data and energy produced in 2011. Compared to the long-term data, those in 2011 are $33 \%$ lower. It should be noted that the 2012 analyses are for the period from January to 
September, i.e. the winter months, which are initially characterized by higher electricity generation, are not taken into account.

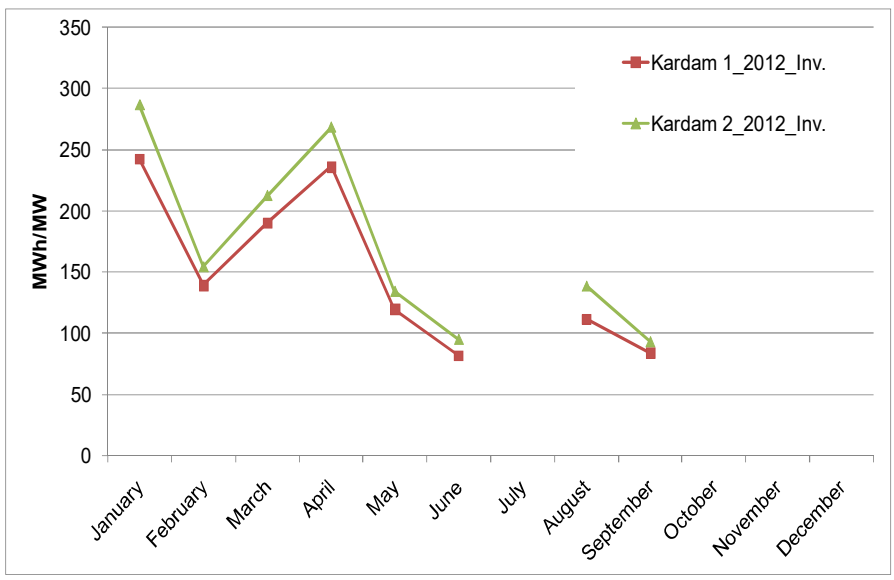

Fig. 9. Invoiced energy per one MW installed power from wind park Kardam 1 and 2 in 2012.

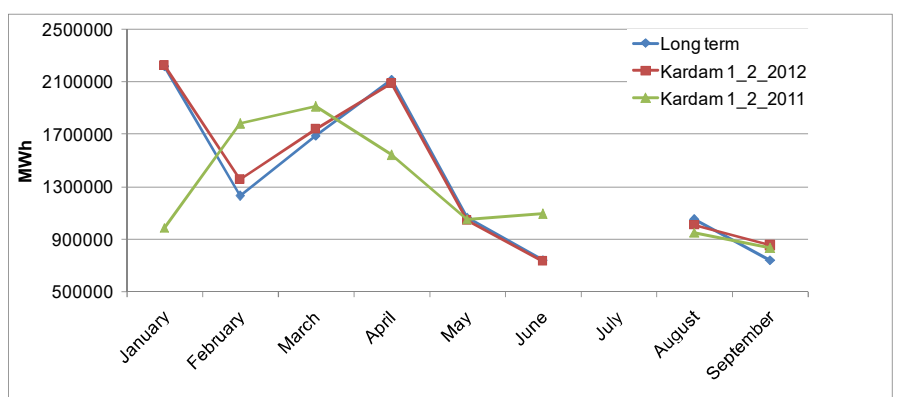

Fig. 10. Energy produced by the four turbines for MW installed capacity in 2011.

Given the above, a $26 \%$ lower energy production gap is significant. This is due both to a change in the average wind speed and its directional distribution.

Figure 11 shows that the average wind speed for 2011 is $5.3 \mathrm{~m} / \mathrm{s}$, in $2012-5.57 \mathrm{~m} / \mathrm{s}$, while according to long-term data the speed is $6.99 \mathrm{~m} / \mathrm{s}$. There is a certain increase in speed in 2012, not taking into account the winter months, and this average should be increased.

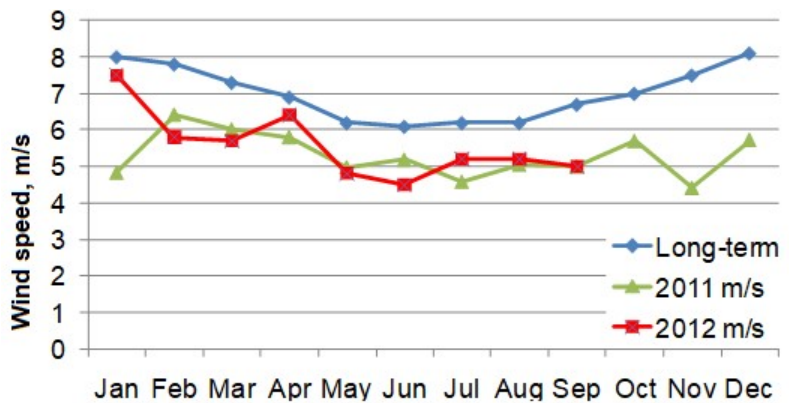

Fig. 11. Wind speed on-site and long-term data

Table 3 shows the change in the average monthly wind speed for 2011, 2012 and the long-term data forecast. The table shows that wind speed in 2011 is $76 \%$ of the forecast, 
and the one in $2012-80 \%$. Expectations are for an increase of correlation coefficient in 2012 because of not considering the data for winter period.

Table 3. Average monthly wind speed values for 2011-2012 compared to long-term ones.

\begin{tabular}{|c|c|c|c|c|c|}
\hline Month & \multicolumn{3}{|c|}{ Mean wind speed, m/s } & \multicolumn{2}{c|}{ Correl, \% } \\
\hline & Long term data & $\mathbf{2 0 1 1}$ & $\mathbf{2 0 1 2}$ & $\mathbf{2 0 1 1}$ & $\mathbf{2 0 1 2}$ \\
\hline Jan & 8 & 4.83 & 7.5 & 60.34 & 93.75 \\
\hline Feb & 7.8 & 6.41 & 5.8 & 82.18 & 74.36 \\
\hline Mar & 7.3 & 6.01 & 5.7 & 82.33 & 78.08 \\
\hline Apr & 6.9 & 5.80 & 6.4 & 84.02 & 92.75 \\
\hline May & 6.2 & 4.97 & 4.8 & 80.16 & 77.42 \\
\hline Jun & 6.1 & 5.18 & 4.5 & 84.93 & 73.77 \\
\hline Jul & 6.2 & 4.58 & 5.2 & 73.87 & 83.87 \\
\hline Aug & 6.2 & 5.04 & 5.2 & 81.30 & 83.87 \\
\hline Sep & 6.7 & 5.00 & 5 & 74.59 & 74.63 \\
\hline Oct & 7 & 5.69 & & 81.30 & \\
\hline Nov & 7.5 & 4.41 & & 58.78 & \\
\hline Dec & 8.1 & 5.72 & & 70.64 & \\
\hline Average & 7.00 & 5.30 & 5.57 & 75.76 & 79.52 \\
\hline
\end{tabular}

Since no significant change in average wind speed should be expected, the last significant factor for energy production is the directional distribution (wind rose).

In Fig. 12 is the wind rose built on the basis of long-term measurements by three different independent companies.

The prevailing wind direction is from North (16\%), North - Northeast $(18 \%)$ and South - Southeast (10\%) a database of wind parameters measured at the hub of the wind turbine.

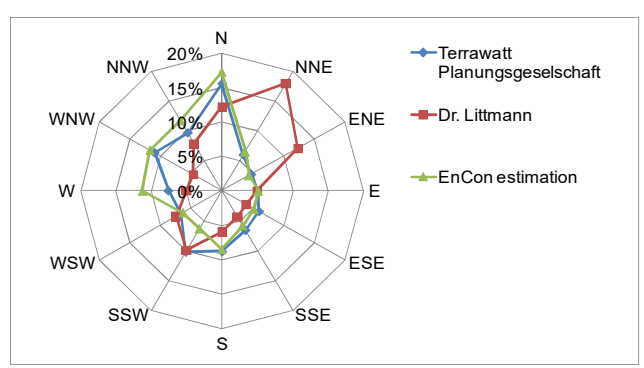

Fig. 12. Predominant wind direction, based on long-term data from 3 independent companies Terrawatt, Dr. Littmann, and EnCon Services. 


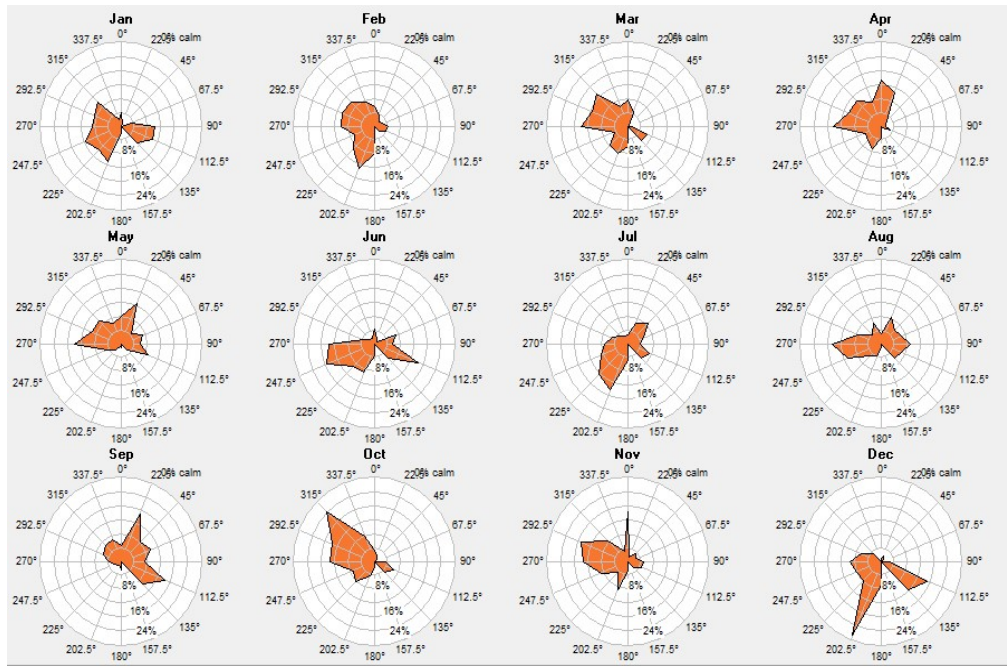

a)

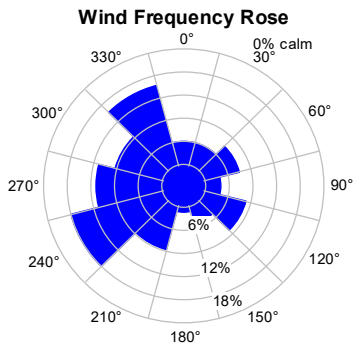

b)

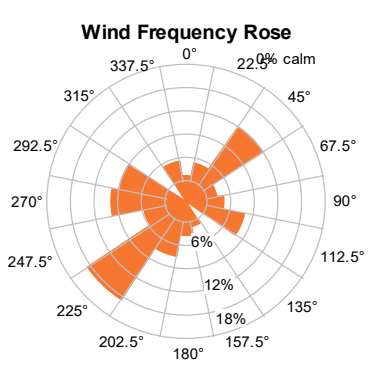

c)

Fig. 13 a) Monthly on-site directional distribution b) wind directional distribution for 2011, c) wind directional distribution for 2012.

In 2011, the higher south-southwest frequency of $18 \%$ and the prevailing NorthNorthwest wind direction shift. The conclusion is that based on the results for 2011 there is a deviation, both in terms of speed and wind direction in relation with long-term data. In 2012 (for the period January - September) (Figure 13c) there is a change in the frequency distribution of the wind in directions but still not significant with the long-term ones.

The better match between the directional distribution shown in Fig. 12 and $13 \mathrm{c}$ is noticeable. This is a prerequisite to believe that the events in 2011 and partly in 2012 may be accepted as random event. For this deviation to be perceived, a similar repeatability of events of at least 3 years should be observed.

In order to perform a detailed analysis between different reference data it is necessary to take into account both the topology of the terrain and the distances between the different measurements. A certain error is expected in determining the estimated annual energy production due to the fact that long-term measurements are carried out $20 \mathrm{~km}$ from a park site.

On the basis of the above, the following can be concluded: the estimated energy production from the selected wind turbines, based on the reference data amounts to 22 $800 \mathrm{MWh} / \mathrm{yr}$. The amount of electricity produced in 2011 by the wind turbines is 14818 $\mathrm{MWh} / \mathrm{yr}$ or about $35 \%$ below the forecast. The difference is due to the fact that in 2011 , the 
wind directional distribution is changed, as well as the wind magnitude - estimated wind speed of the hub height is $5.99 \mathrm{~m} / \mathrm{s}$ and the measured one $-5.3 \mathrm{~m} / \mathrm{s}$ or lower by $11.5 \%$.

In 2012 there is a change in the frequency distribution of the wind in directions approaching the long-term ones. Observed energy production by wind farm in 2012 is $10853 \mathrm{MWh} / \mathrm{yr}$, as the winter period has not been considered in calculations. For accurate analysis the missing data for 2012 are obtained by performing correlation analysis with long-term data from 2010.

Thus, the annual output from the turbines in the park amounts to $18656 \mathrm{MWh} /$ year. This energy production is about $18 \%$ lower than the forecast. The results are presented on table. 4.

Table 4. Power generation from a wind turbine type Suzlon S88 (2012 database correlated with longterm data (2010)).

\begin{tabular}{|c|c|c|c|c|c|c|c|c|c|c|c|c|}
\hline Month & Jan & Feb & Mar & Apr & May & Jun & Jul & Aug & Sep & Oct & Nov & Dec \\
\hline $\begin{array}{l}\text { Speed, } \\
\mathrm{m} / \mathrm{s}\end{array}$ & 7.49 & 5.89 & 5.75 & 6.46 & 4.88 & 4.59 & 5.24 & 5.27 & 5.04 & 5.6 & 5.62 & 6 \\
\hline Weibull k & 3.36 & 2.66 & 2.37 & 3.07 & 2.49 & 2.67 & 2.61 & 2.71 & 2.88 & 2.35 & 2.53 & 2 \\
\hline \multicolumn{3}{|c|}{ Variable } & \multicolumn{2}{|c|}{ Before losses } & \multicolumn{2}{|c|}{ After Losses } & \multicolumn{2}{|c|}{ Units } & & & & \\
\hline \multicolumn{3}{|c|}{ Mean power output } & \multicolumn{2}{|c|}{595} & \multicolumn{2}{|c|}{532} & \multicolumn{2}{|c|}{$\mathrm{kW}$} & & & & \\
\hline \multicolumn{3}{|c|}{ Annual energy output } & \multicolumn{2}{|c|}{5125172} & \multicolumn{2}{|c|}{4664056} & \multicolumn{2}{|c|}{$\mathrm{kWh} / \mathrm{yr}$} & & & & \\
\hline \multicolumn{3}{|c|}{ Capacity factor } & \multicolumn{2}{|c|}{28.3} & \multicolumn{2}{|c|}{25.4} & \multicolumn{2}{|c|}{$\%$} & & & & \\
\hline
\end{tabular}

\section{Conclusion}

The possibility of using reference measurements in terms of wind energy production by a wind farm is investigated. The analysis shows that even in flat or semi-complex terrains, the use of reference data more than $20 \mathrm{~km}$ from the site may lead to a difference in energy production of more than $30 \%$, which is crucial for the profitability of the project. Although the correlation between the separate reference measurements is very good, the local wind parameters during the two years of real wind farm operation show a discrepancy in both the wind rose and the average speed. Because of the above, it is recommended that at least 6 monthly measurements at the farm site should be performed (with portable equipment (Lidar or Sodar)) in order to confirm the satisfactory correlation coefficient with the reference data.

\section{Acknowledgements}

The author would like to thank the Research and Development Sector at the Technical University of Sofia for the financial support.

\section{References}

1. M. Santos, M. González, Factors that influence the performance of wind farms, Renewable Energy, 135, (2019), Pages 643-651

2. V. Bezrukovs, A. Zacepins, V. Bezrukovs, V. Komasilovs, Comparison of methods for evaluation of wind turbine power production by the results of wind shear measurements on the Baltic shore of Latvia, Renewable Energy, 96, Part A, (2016), Pages 765-774

3. S. Rehman, N. M. Al-Abbadi, Wind shear coefficient, turbulence intensity and wind power potential assessment for Dhulom, Saudi Arabia, Renewable Energy, 33, Issue 12, (2008), Pages 2653-2660 
4. G. Gualtieri, S. Secci, Wind shear coefficients, roughness length and energy yield over coastal locations in Southern Italy, Renewable Energy, 36, Issue 3, (2011), Pages 10811094

5. G.K. Gugliani, A. Sarkar, C. Ley, S. Mandal, New methods to assess wind resources in terms of wind speed, load, power and direction, Renewable Energy, 129, Part A, (2018), Pages 168-182

6. W. Werapun, Y. Tirawanichakul, J. Waewsak, Wind Shear Coefficients and their Effect on Energy Production, Energy Procedia, 138, (2017), Pages 1061-1066

7. M. E. Okorie, F. Inambao, Z. Chiguvare, Evaluation of Wind Shear Coefficients, Surface Roughness and Energy Yields over Inland Locations in Namibia, Procedia Manufacturing, 7, (2017), Pages 630-638

8. S. Rehman, N. M. Al-Abbadi, Wind shear coefficients and their effect on energy production, Energy Conversion and Management, 46, Issues 15-16, (2005), Pages 2578-2591

9. K.S.R. Murthy, O.P. Rahi, A comprehensive review of wind resource assessment, Renewable and Sustainable Energy Reviews, 72, (2017), Pages 1320-1342 